\title{
Synthesis and Photoinduced Transformation of a Helical Aromatic Polyamide Having Optically Active Binaphthol Units in the Main Chain
}

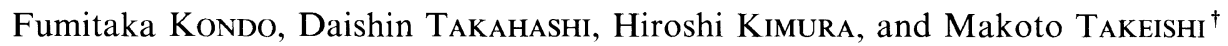 \\ Department of Materials Science and Engineering, Yamagata University, \\ Yonezawa, Yamagata 992, Japan \\ (Received August 11, 1997)
}

KEY WORDS Binaphthol Unit / Helix / Azobenzene / Photoinduced Transformation /

Naturally occurring polymers, such as DNA, protein, and amylose have helical structures essential to biochemical functions. Synthetic helical polymers have also attracted our attention. ${ }^{1}$ Thus, new type of helices have recenthy been reported $^{2}$; among them a photoinduced transformation between $\mathrm{P}$ - and $\mathrm{M}$-helices has been observed with a polyisocyanate carrying chiral azobenzene side chains on the backbone, ${ }^{3}$ in which symmetric change in the $\mathrm{CD}$ spectrum upon photoirradiation indicates reversed helical transformation.

We reported new helical aromatic polyamides obtained by connecting rigid aromatic diamines with axially dissymmetric $(R)$ - or $(S)$-6,6'-dimethylbiphenyl-2,2'dicarbonyl chloride, in which the helical structure is formed by the chiral biphenylene joint in the main chain and the conformational structure is quite stable in $\mathrm{N}$ methylpyrrolidone at $100^{\circ} \mathrm{C}$ because of the restricted rotation around the $\mathrm{C}-\mathrm{C}$ bond between the benzene rings of the joint. ${ }^{4}$ One of them has an azobenzene moiety in the main chain, and photoinduced conformational change of the polymer was examined.

Since chiral binaphthylene joints were also expected to form such helical polymers, we synthesized new helical aromatic polyamides and investigated their properties. High molecular weight aromatic polyamides with $2,2^{\prime}$ binaphthylene units in the main chain are difficult to prepare; accordingly, the synthesis of the polyamides containing 6,6'-binaphthylene units was investigated. ${ }^{5}$ The polymers were prepared by the reaction of a diamine with carbon monoxide and $(R)$ - or $(S)$-6, $6^{\prime}$-dibromo-2,2'dimethoxy-1,1'-binaphthyl (BMBN) obtained in a similar manner as reported, ${ }^{6}$ using a palladium catalyst according to the method of Yoneyama et al. ${ }^{7}$ The properties of the polymers are shown in Table I. Wholly aromatic polyamides (aramides) are insoluble in common solvents; however, all the polymers obtained were soluble in tetrahydrofuran (THF) and pyridine as well as in polar solvents such as $N, N$-dimethylformamide (DMF) and dimethylacetamide, because the conjugated coplanar arrangement of the aromatic rings is hindered by the axially dissymmetric binaphthylene joints. These polymers were made into tough films by the solution-casting method. The specific rotation of IV was higher than that of a model compound prepared from $(R)$-BMBN and 4-aminoazobenzene $\left([\alpha]_{\mathrm{D}}^{25}=-54^{\circ}\right)$. The relatively high specific rotation of the polyamide suggests the

$\dagger$ To whom all correspondence should be addressed. existance of an orderded conformation. The main chains composed of rigid segments are twisted to one-direction by the chiral binaphthylene joint; therefore, an ordered structure of the main chain is likely. The most stable conformation computed for polyamide IV obtained with $(R)$-BMBN shows a right-handed helical structure (Figure 1). The symmetric CD spectra of IV with $(R)$ joints and $\mathbf{V}$ with $(S)$-joints in Figure 2 indicates that

Table I. Synthesis and properties of optically active polyamides $^{\mathrm{a}}$

\begin{tabular}{cccccc}
\hline Polyamides & BMBN & Diamine & Yield $/ \%$ & {$[\alpha]_{\mathrm{D}}{ }^{\mathrm{b}}$} & $\bar{M}_{w}{ }^{\mathrm{c}}$ \\
\hline I & $(R)-(+)$ & PPA & 97 & -90 & 80500 \\
II & $(R)-(+)$ & MDA & 99 & -53 & 48000 \\
III & $(R)-(+)$ & ODA & 98 & -56 & 16400 \\
IV & $(R)-(+)$ & ADA & 100 & -213 & 21300 \\
V & $(S)-(-)$ & ADA & 99 & +218 & 31400 \\
\hline
\end{tabular}

a Polymerization was carried out with $0.5 \mathrm{mmol}$ of BMBN, 0.51 mmol of diamine, $1.1 \mathrm{mmol}$ of 1,8-diazabicyclo[5,4,0]-7-undecene (DBU), $0.03 \mathrm{mmol}$ of $\mathrm{Pd}\left(\mathrm{PPh}_{3}\right)_{4}$, and $0.12 \mathrm{mmol}$ of $\mathrm{PPh}_{3}$ in $2 \mathrm{ml}$ of DMF at $115^{\circ} \mathrm{C}$ under carbon monoxide. ${ }^{b}$ Specific optical rotations of the polymers measured in dimethylacetamide at $25^{\circ} \mathrm{C}$. ${ }^{\mathrm{c}}$ Molecular weights were obtained by combination of GPC and light-scattering data with a polystyrene standard.

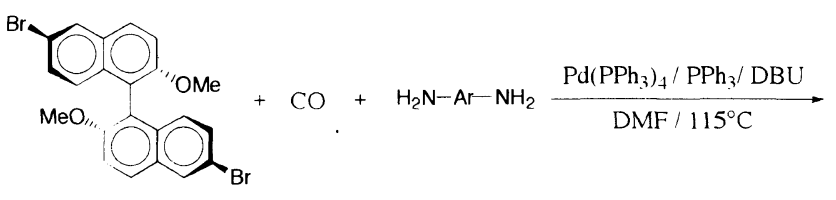

$(R)$-BMBN

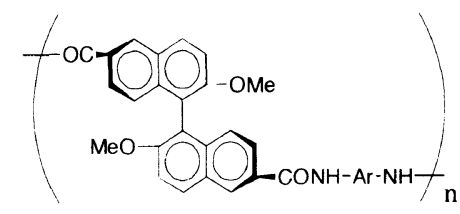

$\mathrm{Ar}$
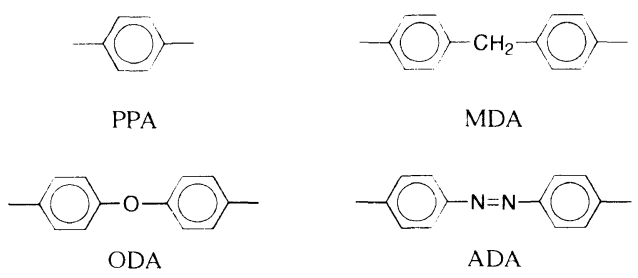

Scheme 1. 


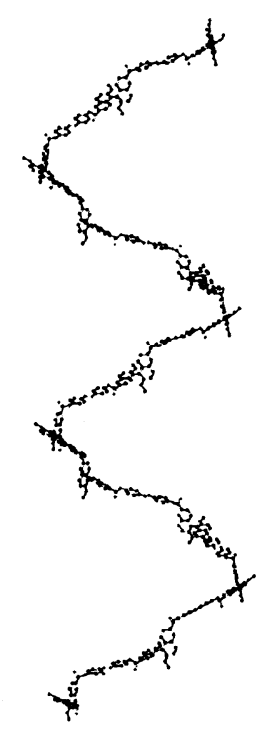

Side view

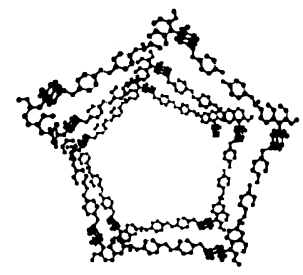

Top view

Figure 1. The most stable conformation of polyamide IV.

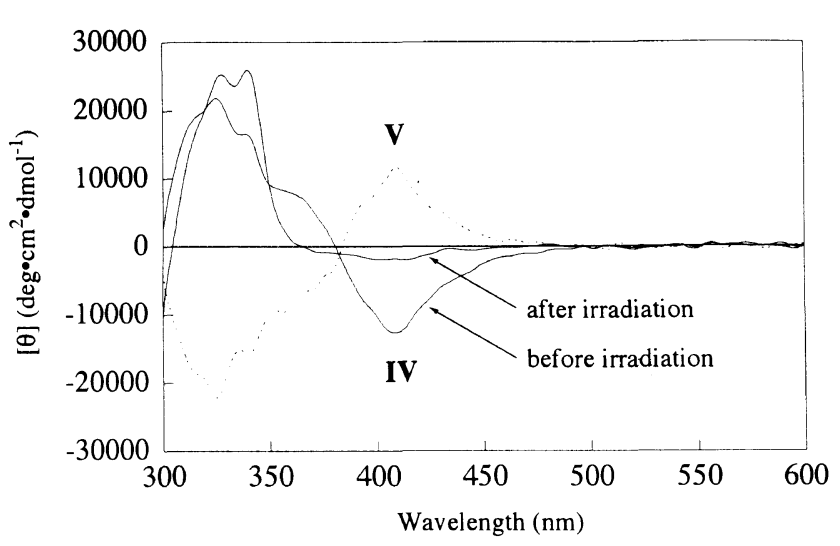

Figure 2. CD spectra of polyamides IV and $\mathbf{V}$, and decreasing dichroic absorption of IV upon irradiation with UV light $(230<\lambda<400 \mathrm{~nm})$ for $15 \mathrm{~s}$.

the two polymers have symmetric structures, that is, two helices with the sence opposite to each other. The $\mathrm{CD}$ in the absorption area of the achiral azobenzene residue around $400 \mathrm{~nm}$ shows that the chromophores are oriented as an axially chiral arrangement.

Azobenzene isomerizes from the trans to the $\mathrm{cis}$ form on irradiation with UV light. When polyamide IV dissolved in dimethylacetamide was irradiated with filtered light $(230<\lambda<400 \mathrm{~nm})$, the absorption with a maximum at $370 \mathrm{~nm}$ due to the trans form decreased rapidly, indicating that the azobenzene segments in the main chain are isomerized to the cis form (Figure 3). The disappeared absorption maximum recovered completely within one minute by reirradiation with visible light $(\lambda>470 \mathrm{~nm})$. This observation is indicative of easy

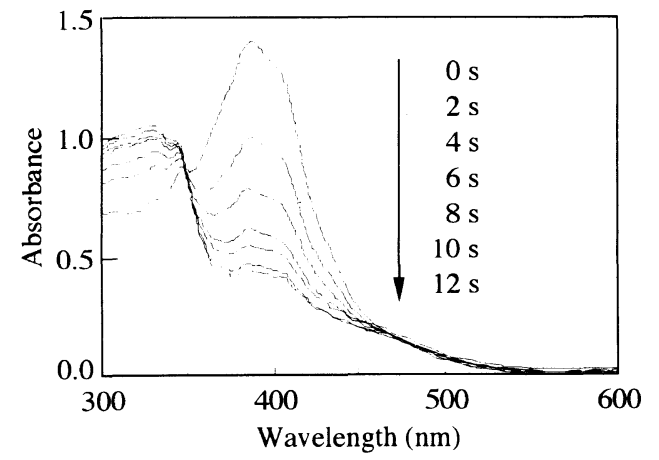

Figure 3. Change in UV spectra of polyamide IV during irradiation with UV light. IV, $6.75 \times 10^{-5} \mathrm{moll}^{-1}$ in dimethylacetamide.

reversible trans-cis isomerization of the azobenzene moiety in the polymer backbone. The specific rotation of polyamide IV decreased on UV irradiation. This implies that the ordered structure is disturbed by the trans-cis isomerization of azobenzene residues. When a solution of the polyamide was irradiated with UV light, the CD spectra changed rapidly because of the trans-cis isomerization of the azobenzene residues as seen in Figure 2. The marked decrease in the molar ellipticity observed for IV on UV irradiation suggests that the helical structure of the polymer is deformed.

In conclusion, a combination of chiral binaphthylene joints and photosensitive rigid segments for polymer synthesis afforded a new type of helical polymer that easily transforms on light irradiation. Practical use of this chirooptical polymer for holographic data storage may be expected because of its photosensitive properties. ${ }^{8}$

\section{REFERENCES}

1. (a) Y. Okamoto and T. Nakano, Chem. Rev., 94, 349 (1994). (b) M. Qin, J. Bartus, and O. Vogl, Makromol. Symp., 98, 387 (1995).

2. (a) Y. Ito, E. Ihara, M. Murakami, and M. Shiro, J. Am. Chem. Soc., 112, 6446 (1990). (b) M. Mikami and S. Shinkai, Chem. Lett., 603 (1995). (c) E. Yashima, T. Nimura, T. Matsushima, and Y. Okamoto, J. Am. Chem. Soc., 118, 9800 (1996).

3. (a) M. Muller and R. Zentel, Macromolecules, 27, 4404 (1994). (b) M. Muller and R. Zentel, Macromolecules, 28, 8438 (1995). (c) M. Muller and R. Zentel, Macromolecules, 29, 1609 (1996).

4. F. Kondo, M. Hidaka, S. Kakimi, H.Kimura, and M. Takeishi, Polym. Prepr., Am. Chem. Soc., Div. Polym. Chem., 38, 209 (1997).

5. (a) R. C. Schulz and R. H. Jung, Makromol. Chem., 116, 190 (1968). (b) Y. Tamai, Y. Matsuzaka, S. Qi, and S. Miyano, Bull. Chem. Soc. Jpn., 64, 2260 (1991).

6. (a) P. V. Bedworth and J. M. Tour, Macromolecules, 27, 622 (1994). (b) H. J. Deussen, E. Hendrickx, C. Boutton, D. Krog, K. Clays, K. Bechgaard, A. Persoons, and T. Bjornholm, J. Am. Chem. Soc., 118, 6841 (1996).

7. (a) M. Yoneyama, M. Kakimoto, and Y. Imai, Macromolecules, 21, 1908, (1988). (b) M. Yoneyama, M. Kakimoto, and Y. Imai, J. Polym. Sci., Part A, Polym. Chem. Ed., 27, 1985 (1989).

8. R. H. Berg, S. Hvilsted, and P. S. Ramanujam, Nature, 383, 505 (1996). 